This item was submitted to Loughborough's Research Repository by the author.

Items in Figshare are protected by copyright, with all rights reserved, unless otherwise indicated.

\title{
Using SCADA data for wind turbine condition monitoring - a review
}

\section{PLEASE CITE THE PUBLISHED VERSION}

http://dx.doi.org/10.1049/iet-rpg.2016.0248

\section{PUBLISHER}

(c) Institution of Engineering and Technology

\section{VERSION}

AM (Accepted Manuscript)

\section{PUBLISHER STATEMENT}

This work is made available according to the conditions of the Creative Commons Attribution-NonCommercialNoDerivatives 4.0 International (CC BY-NC-ND 4.0) licence. Full details of this licence are available at: https://creativecommons.org/licenses/by-nc-nd/4.0/

\section{LICENCE}

CC BY-NC-ND 4.0

\section{REPOSITORY RECORD}

Tautz-Weinert, Jannis, and Simon J. Watson. 2019. "Using SCADA Data for Wind Turbine Condition Monitoring - a Review". figshare. https://hdl.handle.net/2134/22713. 


\title{
Using SCADA data for wind turbine condition monitoring - a review
}

ISSN 1752-1416

Received on 31st March 2016 Revised 7th September 2016 Accepted on 17th September 2016 doi: 10.1049/iet-rpg.2016.0248 www.ietdl.org

\author{
Jannis Tautz-Weinert ${ }^{1}$, Simon J. Watson ${ }^{1}$ \\ ${ }^{1}$ Centre for Renewable Energy Systems Technology, Wolfson School of Mechanical, Electrical and Manufacturing Engineering, Loughborough \\ University, Loughborough, LE11 3TU, UK \\ 凶E-mail: j.tautz-weinert@lboro.ac.uk
}

\begin{abstract}
The ever increasing size of wind turbines and the move to build them offshore have accelerated the need for optimised maintenance strategies in order to reduce operating costs. Predictive maintenance requires detailed information on the condition of turbines. Due to the high costs of dedicated condition monitoring systems based on mainly vibration measurements, the use of data from the turbine supervisory control and data acquisition (SCADA) system is appealing. This review discusses recent research using SCADA data for failure detection and condition monitoring (CM), focussing on approaches which have already proved their ability to detect anomalies in data from real turbines. Approaches are categorised as (i) trending, (ii) clustering, (iii) normal behaviour modelling, (iv) damage modelling and (v) assessment of alarms and expert systems. Potential for future research on the use of SCADA data for advanced turbine CM is discussed.
\end{abstract}

\section{Introduction}

The global capacity of installed wind power stood at $432 \mathrm{GW}$ at the end of 2015 [1]. The industry has long moved on from small clusters of turbines where maintenance access was relatively straightforward and the overhead of sending a maintenance team in at regular intervals was not excessive. In the case of offshore wind farms, in particular, the cost of maintenance relative to the levelised cost of energy (LCOE) is significantly increased compared with onshore. According to Tavner [2], the typical cost of operation and maintenance $(\mathrm{O} \& \mathrm{M})$ as a fraction of the LCOE is between 18 and $23 \%$ compared with $12 \%$ for onshore with recent European offshore $\mathrm{O} \& \mathrm{M}$ costs amounting to between 40 and 44 Euros/MWh [3]. The restrictions imposed by the offshore environment as well as the increasingly large number of machines in a typical wind farm means that maintenance is moving to what in the past would have been scheduled or responsive to a regime that is more predictive and proactive. A key element in this move has been the more intelligent monitoring of wind turbine (WT) state of health, generally termed condition monitoring $(\mathrm{CM})$.

So-called condition monitoring systems (CMS) have been developed by a number of manufacturers. These monitor several key parameters including drive train vibration, oil quality and temperatures in some of main subassemblies. Such systems are normally installed as additional 'add-ons' to the standard WT configuration. The significant costs of CMS - usually more than 11,000 Euros per turbine [4] - has deterred operators from installing these systems, although the financial benefit of early fault detection by CMS has been proven [5]. However, all large utility scale WTs have a standard supervisory control and data acquisition (SCADA) system principally used for performance monitoring. Such systems provide a wealth of data at normally 10minute resolution, though the range and type of signals recorded can vary widely from one turbine type to another. As CM using SCADA data is a potentially low cost solution requiring no additional sensors, a number of approaches using these data for early failure detection have been developed in recent years.

A number of general literature reviews of WT CM have been conducted in the last decade to gather together information on new approaches and techniques. A comprehensive collection of $\mathrm{CM}$ techniques sorted by $\mathrm{CM}$ system and fault detection for different subsystems was provided by Hameed et al. [6]. An overview of $\mathrm{CM}$ methodologies and signal processing techniques complemented by a fault tree analysis were given in [7]. A systematic literature review in [8] revealed the geographical contribution to this research topic and listed different approaches. An extensive review linked monitoring techniques with possible failures [9]. Considerations of the advantages, disadvantages, costs, online feasibilities, fault diagnosis abilities and deployment statuses of CM methodologies were discussed in [5]. The latest review considering complexity, capability, signal-to-noise ratio, sampling frequency and cost of multiple approaches was given in $[10,11]$. However, to date, there has not yet been a detailed review of the use of SCADA data for the CM of WTs. In this paper, the use of SCADA data in this regard is covered including the potential for monitoring different subassemblies and the ways in which SCADA data are actually used to predict, diagnose and prognose failure.

In the next section, WT reliability and failure rates of subassemblies are briefly reviewed. The next and main part of this paper addresses the use of SCADA data for CM. The final section discusses the strengths and weaknesses of the different approaches reviewed and highlights areas for future research.

\section{Failure statistics}

Several surveys of WT failures have been conducted in the last two decades to identify failure rates and associated downtime for different subassemblies. However, the different taxonomies used by different turbine manufacturers, wind farm operators and researchers make comparisons between these surveys challenging.

The evaluation of 15 years of data from the German ' $250 \mathrm{MW}$ Wind' programme [12] and $>95 \%$ of all the turbines operating between 1997 and 2005 in Sweden [13] gave first insights into the reliability of the first onshore WTs. The German turbines had an average availability of about $98 \%$. An average failure rate of 0.4 failures per turbine per year resulted in an average downtime of 130 hours per turbine per year for the Swedish turbines. A distinctive difference between failure rate and downtime distribution in subassembly groups was identified. The electrical and electronic control systems were identified as the most failureprone, but gearbox and generator failures caused the longest downtime.

An evaluation of the Windstats newsletter providing statistics for turbines in Denmark and Germany for a similar time range revealed differences in failure rates of WTs in the two countries [14]. Higher failure rates for the German turbine population were traced back to the different age and the newer (but less mature) 
variable speed and pitch control technology employed in German turbines. The electrical system was the most failure-prone subassembly in the German turbine population, whereas the Danish population was mostly affected by yaw system and so-called 'unclassified' failures. Records of the Chamber of Agriculture in Schleswig-Holstein, Germany, confirmed the failure rates for German WTs [15]. The different studies up to this time agreed that the gearbox had been the source of failure with the longest downtime [16]. An analysis of the first operating years of the UK Round 1 offshore wind farms revealed availabilities of only $80.2 \%$. The main causes for this relatively low availability were found to be gearbox and generator bearing problems [17]

A more recent failure survey was conducted as part of the Reliawind project [18]. In this survey, 35,000 downtime events from 350 WTs were evaluated. The order of the subsystem failure rates was found to be led by the power module assembly followed by rotor module, control system, nacelle and drive train in descending order. The three most failure-prone subassemblies were identified as the pitch system, frequency converter and the yaw system. The downtime hierarchy was very similar to the failure rate order. This finding was in contrast to previous studies, which found that the gearbox was the greatest contributor to unscheduled turbine downtime.

A report from the National Renewable Energy Laboratory (NREL) in the US [19] stated that approx. $70 \%$ of gearbox failures were caused by bearing faults and approx. $26 \%$ by gear teeth faults based on a database of 289 failure events collected from 20 partners since 2009.

Carroll et al. [20] compared failure rates in the first five years of 1822 turbines with doubly-fed induction generators (DFIGs) with 400 turbines using a permanent magnet generator (PMG) with a fully rated converter. For the PMG turbines, a lower generator failure rate was found to be accompanied by a much higher failure rate in the converter.

The most recent analysis of failure statistics from Carroll et al. [21] looked at data from around 350 relatively new offshore

Table 1 Basic SCADA parameters according to [4, 5, 2229]

\begin{tabular}{|c|c|c|c|}
\hline Environmental & $\begin{array}{c}\text { Electrical } \\
\text { characteristics }\end{array}$ & $\begin{array}{c}\text { Part } \\
\text { temperatures }\end{array}$ & $\begin{array}{c}\text { Control } \\
\text { variables }\end{array}$ \\
\hline wind speed & $\begin{array}{l}\text { active power } \\
\text { output }\end{array}$ & gearbox bearing & pitch angle \\
\hline wind direction & power factor & $\begin{array}{c}\text { gearbox lubricant } \\
\text { oil }\end{array}$ & yaw angle \\
\hline $\begin{array}{l}\text { ambient } \\
\text { temperature }\end{array}$ & reactive power & $\begin{array}{l}\text { generator } \\
\text { winding }\end{array}$ & $\begin{array}{l}\text { rotor shaft } \\
\text { speed }\end{array}$ \\
\hline \multirow[t]{12}{*}{$\begin{array}{l}\text { nacelle } \\
\text { temperature }\end{array}$} & $\begin{array}{l}\text { generator } \\
\text { voltages }\end{array}$ & $\begin{array}{l}\text { generator } \\
\text { bearing }\end{array}$ & $\begin{array}{l}\text { generator } \\
\text { speed }\end{array}$ \\
\hline & $\begin{array}{l}\text { generator phase } \\
\text { current }\end{array}$ & main bearing & $\begin{array}{l}\text { fan speed / } \\
\text { status }\end{array}$ \\
\hline & voltage frequency & rotor shaft & $\begin{array}{l}\text { cooling pump } \\
\text { status }\end{array}$ \\
\hline & & generator shaft & $\begin{array}{c}\text { number of } \\
\text { yaw } \\
\text { movements }\end{array}$ \\
\hline & & $\begin{array}{l}\text { generator slip } \\
\text { ring }\end{array}$ & $\begin{array}{l}\text { set pitch } \\
\text { angle / } \\
\text { deviation }\end{array}$ \\
\hline & & inverter phase & $\begin{array}{l}\text { number of } \\
\text { starts / stops }\end{array}$ \\
\hline & & $\begin{array}{l}\text { converter cooling } \\
\text { water }\end{array}$ & $\begin{array}{l}\text { operational } \\
\text { status code }\end{array}$ \\
\hline & & $\begin{array}{l}\text { transformer } \\
\text { phase }\end{array}$ & \\
\hline & & hub controller & \\
\hline & & top controller & \\
\hline & & $\begin{array}{l}\text { converter } \\
\text { controller }\end{array}$ & \\
\hline & & grid busbar & \\
\hline
\end{tabular}

turbines from one manufacturer recorded over a 5 year period at 5 10 wind farms. The failure rates were highest for the pitch/ hydraulic subassembly, followed by 'other components' and the generator, but only those failures were considered where unscheduled maintenance visits were made. Analysis of the failure rate by year of operation showed a decrease in the first five years. A comparison with onshore turbines [20] suggested higher failure rates offshore, but not as high as expected given the different turbine populations and environmental characteristics. Analysis of average repair times, material costs and the number of required technicians indicated that blades, hub and gearbox were the most critical subassemblies in this context.

\section{Review of approaches to utilise SCADA data for $\mathrm{CM}$}

This review focuses on CM approaches, which have already been applied using real data from operational WTs. Different methods have been developed, which are classified as (i) 'trending', (ii) 'clustering', (iii) 'normal behaviour modelling' (iv) 'damage modelling' and (v) 'assessment of alarms and expert systems'. Class (v) covers how alarm logs and modelling results can be automatically interpreted. The usage of SCADA data for purposes besides CM is briefly outlined in (vi) 'other applications'.

The parameters typically recorded by SCADA systems of geared-drive turbines are listed in Table 1. In general, SCADA records are 10-minute averages of $1 \mathrm{~Hz}$ sampled values. However, maximum, minimum and standard deviation are often recorded as well. The number of starts and stops and alarm logs recorded by the SCADA system can also be seen as part of CM [22]. Vibrations $[4,30]$, oil pressure level and filter statuses [31] could be recorded by a WT SCADA system too, but these are commonly recorded separately in a what might be termed a 'dedicated' CMS. There is no such thing as a standard set of monitoring equipment or measurement nomenclature for the different turbine populations seen today. Nevertheless, a general trend has been seen for the installation of more sensors in modern turbines. An overview of commercially available SCADA systems is given in $[5,32]$.

\subsection{Trending}

Although WT SCADA systems have not been developed specifically for the purposes of CM, using SCADA data to monitor the health of turbines has been investigated as soon as optimising maintenance became a high priority in the wind industry. The main challenge lies in how to interpret trends given the variability in the operational conditions of modern WTs. A change in the value of a SCADA parameter is accordingly not necessarily evidence for a fault. One of simplest approaches is to collect data over a long period and monitor ratios of SCADA parameters and how they change over time. Past studies have involved trying to find early signs of degradation by using such trending approaches.

Research in the condition monitoring for offshore wind farms project carried out from 2002 to 2007 included SCADA CM techniques [33]. Simple trending methods e.g. using regression lines in scatter diagrams of temperature against power or threedimensional visualisations including the ambient temperature were suggested. Manual interpretation of filtered SCADA data comparisons was seen as beneficial for detecting anomalies. Due to the lack of faults during the measurement campaign conducted on five turbines, detailed algorithms were not developed.

Kim et al. [34] investigated a Principal Component Analysis trending approach with an auto-associative neural network. The structure of this network consisted of one input layer, a mapping layer, a bottleneck layer, a de-mapping layer and an output layer. After training with data from normal operation, the network produced a set of principal components, which were evaluated using the Q-statistic (a measure of uncaptured variation) and the Hotelling $T^{2}$ statistic (a measure of the model variation). Testing the approach using a known fault case from the $600 \mathrm{~kW}$ control advanced research Turbine 2 located at NREL proved the general ability to detect a failure thought no advance signs of the fault were 


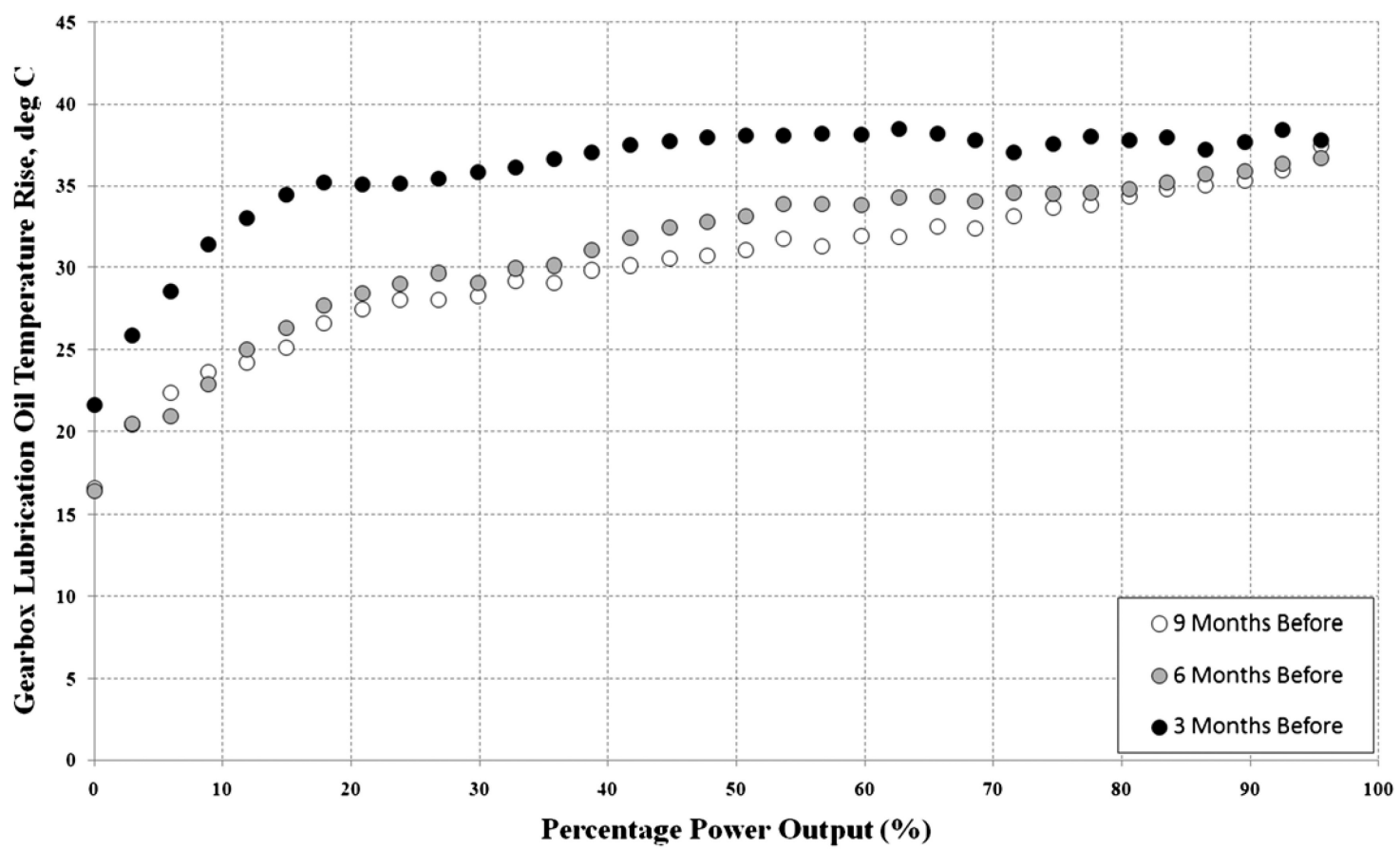

Fig. 1 Gearbox oil temperature rise by power bin during a developing failure from [31]. Reprinted from [31], Copyright 2012 with permission of John Wiley and Sons, Ltd
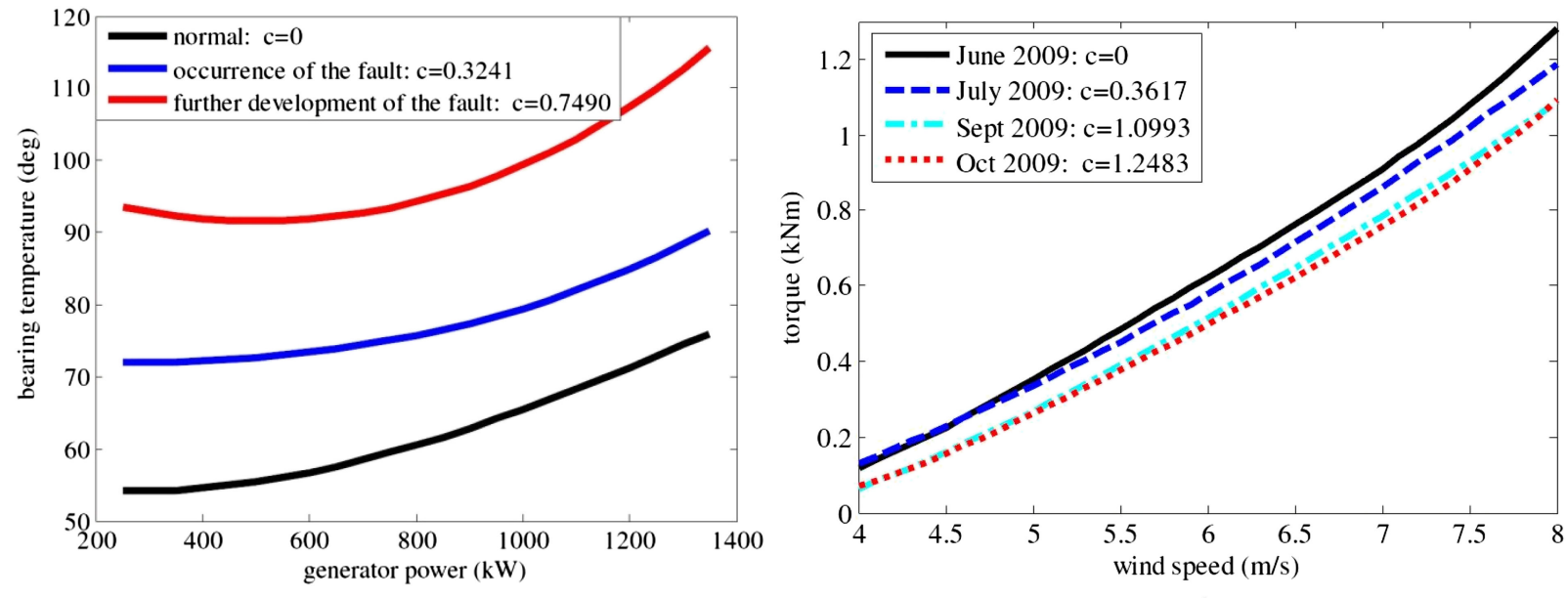

Fig. 2 Generator bearing fault detected through generator bearing temperature and blade deterioration detected through generator torque for different stages of the faults. In addition, a calculated CM fault severity parameter ' $c$ ' is shown [4]. Reprinted from [4], Copyright (2013), with permission from Elsevier

(a) Generator bearing fault detection in filtered bearing temperature, (b) Blade deterioration detection in filtered torque (calculated from generator power and rotor speed)

detected. Testing using another control data set where no known faults occurred showed that false detections could occur.

Feng et al. [31, 35] showed that if the gearbox efficiency decreases, the gearbox temperature rise (compared with the ambient temperature) will increase. Example gearbox oil temperature trends from a case study of a $2 \mathrm{MW}$ variable speed turbine are shown grouped by power bin in Fig. 1. The deterioration of the gearbox is already visible 6 months before a catastrophic planetary gear failure.

Yang et al. [4] proposed a trending method using bin averaging by wind speed, generator speed or output power. Two case studies with real turbines were analysed: a three-bladed turbine with a generator bearing failure; and a two-bladed turbine with a blade failure as shown in Figs. $2 a$ and $b$, respectively. A CM quantifying criterion (denoted ' $c$ ') based on a correlation model of historic and present data was proposed as a way of detecting levels of damage, though the value of the criterion has a different scale depending on the damage mode and dependent parameter.

Astolfi et al. [36] investigated trending of temperatures against the rated power over different time scales. Comparisons of results for a nine turbine onshore wind farm of $2 \mathrm{MW}$ turbines were made. Historical and real time analyses helped the operator to detect problems.

Wilkinson et al. [28] investigated different methods of using SCADA data for CM. One approach included a simple comparison of temperature trends of different turbines in a particular wind farm. The authors ultimately dismissed this approach due to inaccuracy resulting from differing environmental conditions or operational modes in a wind farm.

Trending of SCADA parameters, especially drive train temperatures, can reveal the development of a failure using historical data. However, different studies have shown that changes in temperature are highly case-specific and require manual interpretation. Using a numerical description of the trend instead of visual interpretation of scatter diagrams did not prove to be beneficial. If trending is to be used for online monitoring, difficulties in the interpretation of changes and the setting of thresholds will most likely result in high uncertainties and possibly false alarms. 


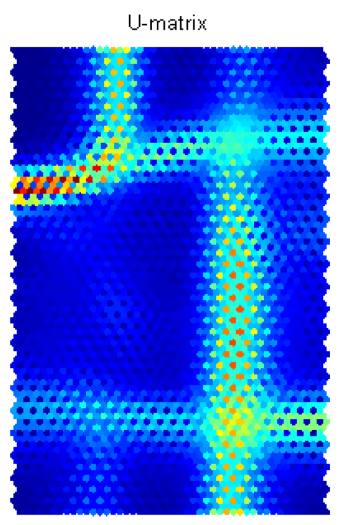

a
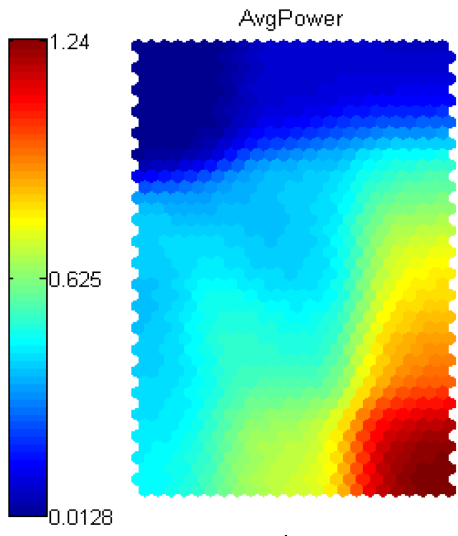

$b$
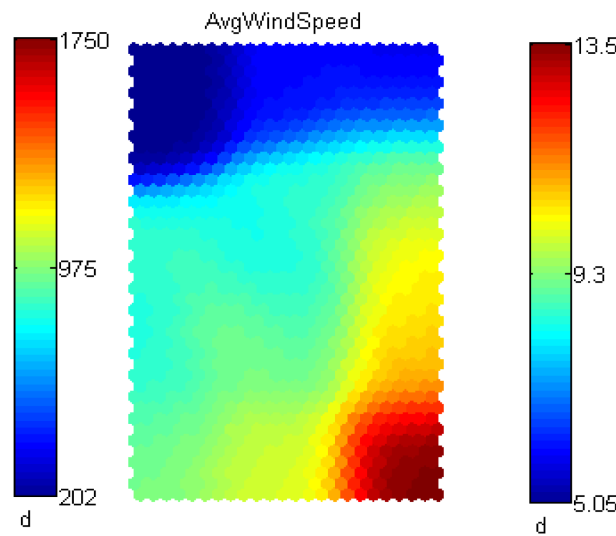

Fig. 3 General self-organising map example from [25] showing in particular one cluster in the upper left-hand side and one in the lower right-hand side corner. Reprinted with permission of [25]. Copyright 2011, RES Offshore

(a) Unified distance matrix. Higher values indicate a greater Euclidean distance between the nodes, (b) Power output component plane, (c) Wind speed component plane

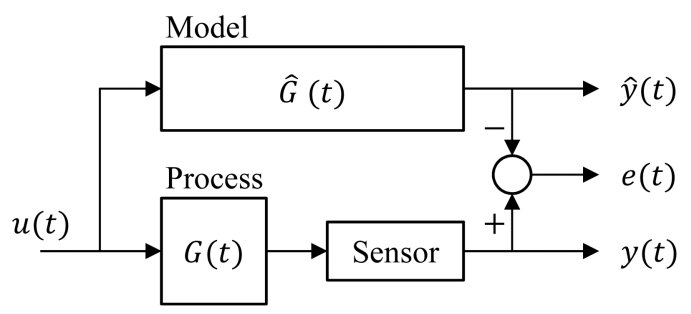

Fig. 4 Model-based monitoring with the input $u(t)$ for both the process $G(t)$ and its model $\hat{G}$, their outputs $y(t)$ and $\hat{y}(t)$, respectively, and the final error or residual $e(t)$. Sketch adapted from [39]

\subsection{Clustering}

Visual interpretation of trends can be problematic if a large fleet of WTs operating under very different conditions is to be monitored cost-effectively. A next step in the evolution of CM with SCADA data was the application of clustering algorithms to automate the classification of 'normal' and 'faulty' observations.

Kusiak and Zhang [37, 38] analysed WT vibrations using SCADA records including drive train and tower acceleration. Vibrations were grouped by a modified k-means clustering algorithm conditioned on the wind speed. Abnormal vibrations were detected by measuring the Euclidean distance between data and cluster centroids built in an initial training period. Limitations in determining the boundaries of clusters and the missing description of temporal changes were acknowledged and subsequently a normal behaviour modelling approach was pursued.

Catmull [25] and Kim et al. [34] were the first to apply an artificial neural network (ANN) self-organising map approach to SCADA data. The method builds clusters by rearranging neurons on a regular grid during the training process in a way that neighbouring neurons denote similar input data. A unified distance matrix can be used to visualise the clustering. In combination with projections of parameters, this enables interpretation of the clustering. Fig. 3 shows a general example of a clustering with selforganising maps. Catmull used only normal operational data for training and proposed the calculation of the distance between new input data and the best matching neuron, called quantisation error, for abnormality detection. Example applications of the method using data from WTs with a sensor error, reactive power loss and an unidentified generator failure showed a general ability to detect failures. Kim et al. used a training data set, which included failures. They were then able to assign subsequent WT failures to corresponding clusters. Wilkinson et al. [28] pursued Catmull's approach and presented some examples of detecting gearbox failures comparing the quantisation error for multiple turbines.

From the evidence reviewed, the clustering of healthy and faulty observations has not shown a clear advantage in terms of CM compared with trending algorithms, as the interpretation of results is again difficult. In addition, using fault data for training is not necessarily feasible in an industrial setting.

\subsection{Normal behaviour modelling (NBM)}

NBM uses the idea of detecting anomalies from normal operation as used in the previous methods, but tries to empirically model the measured parameter based on a training phase. Fig. 4 illustrates the idea of model-based monitoring. The residual of measured minus modelled signal acts as a clear indicator for a possible fault: it is assumed to be approx. 0 with a given tolerance for normal conditions and not equal to 0 for changed conditions or failures. Two main concepts for NBM can be differentiated: Full Signal ReConstruction (FSRC), where only those signals, other than the target are used to predict the target, and AutoRegressive with eXogenous input modelling (ARX), where historic values of the target are also used.

3.3.1 Linear and polynomial models: The simplest form NBM is based on linear or polynomial models. Garlick et al. [39] used a linear ARX model to detect generator bearing failures in the bearing temperature. A cross-correlation analysis was conducted, i.e. the sample cross-correlation was computed as an estimate of the covariance between the target signal and each possible input. The correlation analysis determined that the generator winding temperature was the best exogenous input. Different numbers of polynomial parameters were investigated and evaluated with the coefficient of determination and Akaike's information criterion. 3 years of SCADA data for 12 turbines were evaluated with a threeparameter model trained with one day of data. Some of the detected anomalies were found to correlate with fault log reports.

Cross and Ma [30] investigated different NBM approaches using SCADA data from 26 turbines and 16 months of operation. Gearbox and generator winding temperatures were modelled using wind speed and active power in an ARX model. The coefficients of determination were only moderate for normal operation with 0.710 and 0.833 for the gearbox and winding temperature, respectively. No detailed study on linear models was conducted, as other approaches were considered as more suitable.

Wilkinson et al. [28] developed higher order polynomial FSRC models for NBM of drive train temperatures with different SCADA inputs based on correlation analysis and the physics of the system. Data from the same turbine, different turbines at the same site as well as different turbines at different sites were used. The developed algorithms were blind tested on 472 turbine years of data from five different wind farms. Examples of successful detection of gearbox and main bearing failures by modelling of a bearing or gearbox temperature with rotor speed, power output and the nacelle temperature were presented. Overall, 24 of 36 component failures were detected with only three false alarms with accuracy highly dependent on the wind farm. The algorithm resulted in detection of failures from one month to two years in advance.

Schlechtingen and Santos [40] developed a linear model based on up to 14 months of SCADA data from ten $2 \mathrm{MW}$ offshore WTs. The linear FSRC model for the generator bearing temperature built 


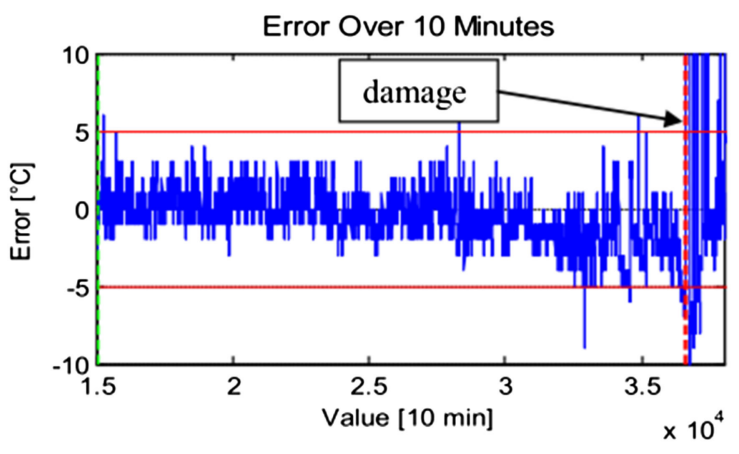

a

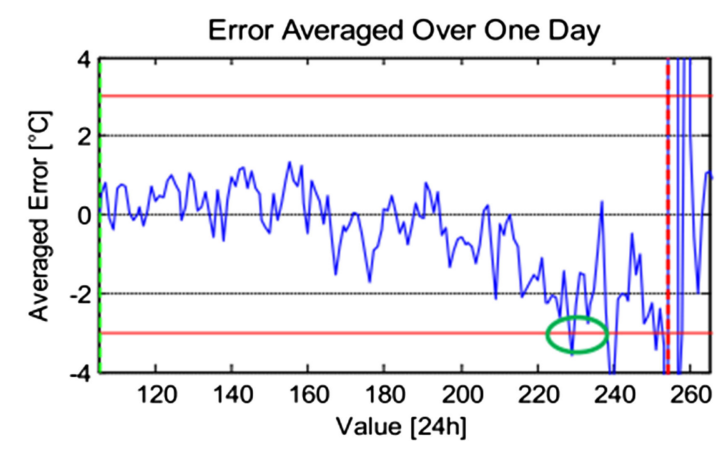

Fig. 5 Regression based generator bearing temperature modelling showing a catastrophic failure [40]. If the residual of measurement minus modelled temperature ('error') is higher than the threshold, damage is likely. Reprinted from [40], Copyright (2010) with permission from Elsevier

(a) 10 minute prediction error, (b) Daily averaged prediction error

with generator power output, nacelle temperature and shaft speed as inputs predicted the target temperature with an accuracy of $\pm 4^{\circ} \mathrm{C}$ after filtering. A catastrophic generator bearing failure of one turbine was successfully detected as shown in Fig. 5. The use of daily averages of the residual was demonstrated to be plausible for the purposes of fault detection. The first alarm limit violation was 25 days prior to the damage.

3.3.2 Artificial neural network: ANNs are a way of determining non-linear relationships between observations using training data. The basic architecture for modelling contains one input layer, a variable number of hidden layers and one output layer. Each layer consists of different numbers of neurons, which are fed by all inputs or other neuron outputs from the previous layer. The basic learning of the network involves the changing of input weights. Each neuron consists of a nonlinear transfer function to combine the inputs and an activation function deciding if output is generated. Common networks are feed-forward, i.e. only with links from lower to higher layers, in contrast to recurrent architectures $[24,41]$.

Garcia et al. [23] developed an intelligent system for predictive maintenance called SIMAP based on ARX NBM with ANNs. Table 2 shows the inputs used in this work for modelling of the gearbox bearing temperature, the cooling oil temperature and the difference in the cooling temperature before and after the gearbox determined by cross-correlation and impulse response analyses. A

Table 2 Inputs for ANN based modelling in SIMAP [23] reprinted from [23], Copyright (2006) with permission from Elsevier

\begin{tabular}{lcc}
\hline Model & Type & Inputs \\
\hline gearbox bearing & multilayer & gearbox bearing temperature $(t-$ \\
temperature & perceptron & $1, t-2)$ \\
model & &
\end{tabular}

generated power $(t-3)$

nacelle temperature $(t)$

cooler fan slow run $(t-2)$

cooler fan fast run $(t-2)$

gearbox thermal multilayer gearbox thermal difference $(t-1)$ difference model perceptron

generated power $(t-2)$

nacelle temperature $(t)$

cooler fan slow run $(t-2)$

cooler fan fast run $(t-2)$

cooling oil multilayer cooling oil temperature $(t-1)$ temperature perceptron model confidence level of $95 \%$ was proposed resulting in lower and upper bands for the detection of anomalies by comparison with measured values. Garcia et al. did not provide details of the ANN configuration and training algorithm or any results of a detailed case study.

Zaher et al. [24] investigated ANN based gearbox bearing and cooling oil temperature modelling and demonstrated its ability using 2 years of SCADA data for 26 Bonus $0.6 \mathrm{MW}$ stall-regulated turbines. An ANN with 3 neurons in the hidden layer was presented as the best architecture. The inputs for the two investigated FSRC models were based on cross-correlation and included values from previous time-steps. Roughly 13,000 training data points were manually chosen to represent normal behaviour. Zaher et al. were able to detect a gearbox fault in one turbine with the trained model. Overheating problems were detected almost 6 months before the failure of one turbine. The interpretation of the highly fluctuating residual with several spikes was not conclusively explained, as no simple threshold would result in the depicted diagnosis.

Brandão et al. [42, 43] applied a FSRC ANN approach to gearbox and generator fault detection in a Portuguese wind farm with 13 turbines with $2 \mathrm{MW}$ rated power and an US farm consisting of 69 turbines with $1.5 \mathrm{MW}$ rated power. The inputs were chosen based on cross-correlation and included appropriate delays. It was stated that at least 6 months' training data were needed, but details of settings were not provided. A fixed value of the mean absolute error was used as an alarm level, although this value was specific and not valid after maintenance actions.

Schlechtingen and Santos [40] compared a linear model (as described earlier) with two different ANN model configurations in a study of up to 14 months' SCADA data from ten $2 \mathrm{MW}$ offshore WTs. The FSRC model used the generator stator temperature, nacelle temperature, power output and generator speed to predict the generator bearing temperature. The second model, an ARX approach, used additional historic values of the generator bearing temperature. A feed-forward network with one hidden layer with 5 or 6 neurons for FSRC and ARX modelling, respectively, was trained with three months of data. Input pre-processing was applied including: checking against the means of data ranges, checking for large changes in observations, normalisation of data, exclusion of records with missing data and lag removal based on crosscorrelation. The accuracy of the FSRC model was comparable with the linear approach, whereas the ARX model showed errors of only $\pm 2^{\circ} \mathrm{C}$ most of the time. Using daily average prediction errors was demonstrated to be beneficial. All models were able to detect bearing damage prior to a catastrophic failure. The alarm was triggered earlier in the case of the ANN models compared with the linear model. A further disadvantage of the linear model was seen in a strong seasonality of the prediction error. Two other investigated bearing damage events were detected by the ANNs about 185 days ahead with up to 5 days difference between FSRC and ARX models. The FSRC model allowed easier identification of the bearing failures due to larger shifts in the mean. Another advantage of the FSRC model was seen in the possible identification of sensor problems due to the monitoring of absolute 
changes in the reconstructed signal. Higher false alarm rates were expected for the FSRC model, however.

Kusiak and Verma [44] studied bearing fault detection using four months' SCADA data in $10 \mathrm{~s}$ resolution from $241.5 \mathrm{MW}$ turbines. The input parameters for the FSRC model were selected firstly using physical understanding of the system and next by one of three data mining algorithms: wrapper with genetic search, wrapper with best first search and boosting tree algorithm. The differences between the five tested ANN configurations were in the number of neurons (5-25) and activation functions (tanh, exponential, identity, logistics). The best configuration consisted of 18 neurons, logistic hidden activation and identity output activation. NBM was successfully demonstrated and abnormal bearing behaviour during one week of data for one turbine was analysed.

Kusiak and Zhang $[37,38]$ modelled WT drive train and tower accelerations from SCADA data at $10 \mathrm{~s}$ resolution. Two fault code situations were studied using a few days of data from six variable speed 1.5 MW turbines. The models used for fault detection were ANN, ANN ensemble, boosting regression tree, support vector machine, random forest with regression, standard classification and regression tree and k-nearest-neighbour ANN. Modelling used several time-steps of wind speed, 'wind deviation' (assumed to stand for yaw error), blade pitch angle, generator torque and previous time-steps of the target variable as inputs using an ARX approach. Details of the algorithm settings were not provided, but results under normal conditions showed that the ANN and the ANN ensemble performed best for modelling drive train and tower acceleration, respectively. In a second approach, the accelerations were successfully modelled with inputs from two different turbines (here called virtual sensor concept). Detection of two anomalies in the data set was demonstrated.

Zhang and [45] applied ARX ANN modelling to the main shaft rear bearing temperature in direct-drive turbines. Based on approx. one year of data from two $3 \mathrm{MW}$ turbines in a $17 \mathrm{WT}$ farm, a failure in one turbine was detected three months ahead with a model using output power, nacelle temperature and turbine speed as exogenous inputs. The anomaly threshold was set to $1.5^{\circ} \mathrm{C}$ for the residual and was validated with normal operation from a second turbine.

Li et al. [46] built a monitoring system utilising an ANN for modelling component temperatures, power output and rotor speed based on data from $341.5 \mathrm{MW}$ turbines. Temperatures were modelled in an ARX approach using current wind speed, ambient temperature and the output power as exogenous inputs. The authors stated that a specific model needs to be tuned to each individual turbine and is influenced by seasonal variations of wind speed and ambient temperature. A mean absolute error for normal conditions of $0.67-0.91{ }^{\circ} \mathrm{C}$ was stated. Failure detection using a 'health degree' measure utilised penalty factors for residuals in the outer regions of a probability distribution. Sun et al. [29] investigated a revised system with additional models trained using either samples from a time period one year before or measurements on other turbines. Although the traditional models trained with up-to-date data of the same turbine perform best, the other models were beneficial in anomaly detection, where their prediction errors were weighted based on the accuracy under normal conditions. Two case studies highlighted the advantages of the anomaly detection system compared with simple residual thresholds or single-model based assessment. A further 14 fault cases were identified with $93.25 \%$ detection accuracy.

Cross and Ma's [30] second approach to NBM used ANN. The gearbox bearing temperature, generator winding temperature and active power output were predicted in an ARX approach using wind speed as an exogenous variable. Ten neurons with a sigmoidal transfer function were applied in the hidden layer. NBM with ANN resulted in high coefficients of determination significantly outperforming two other investigated approaches, namely linear and state dependent parameter (SDP) modelling. In a multivariate setting with the active power as a second exogenous input, the SDP modelling was more accurate, however.

Bangalore and Tjernberg [47] applied an ANN for NBM of gearbox bearing temperatures in an ARX configuration. The selection of the training data was automated by using filtering and selection [48]. Self-evolution by automatically updating the ANN after maintenance actions was suggested [49]. Anomalies were detected by considering residual and target distributions from the training period in a Mahalanobis distance. Five ANNs were built to model temperatures of five bearings in a common gearbox based on data from an onshore $2 \mathrm{MW}$ turbine. All ANNs used power, gearbox oil temperature, nacelle temperature and the rotational speed as inputs as well as up to two additional temperatures of the other investigated bearings. The Mahalanobis distance was averaged over three days and compared with a threshold defined by training results. A recorded gearbox failure due to spalling in one bearing was successfully detected by the approach one week before the vibration-based CM system identified the failure. Comparison with root mean square errors emphasised the advantage of the Mahalanobis distance in detecting anomalies earlier.

3.3.3 Fuzzy system: A fuzzy inference system evaluates inputs with if-then rules based on fuzzy logic, i.e. degrees of truth instead of Boolean logic (true/false). Membership functions define how inputs are mapped to a fuzzy value. If-then rules are built of two parts: the 'if' - the 'antecedent' with the evaluation of the input membership(s) and the 'then' - the 'consequence' applying the rule and returning a fuzzy output or an output as a function of the inputs (Sugeno fuzzy model) [50].

Schlechtingen et al. [27] proposed an Adaptive Neuro-Fuzzy Inference System (ANFIS) for NBM. ANFIS can be described as network-based learning of membership functions of fuzzy inference systems. Three years of SCADA data from 18 onshore 2 MW turbines were used as the basis of this research. Two rules with generalised normal distribution membership functions were applied for each input. Depending on the target variable and its physical properties, reconstruction with signals of a different sensor type or of the same type (cross prediction, e.g. temperature of another phase of the generator) were chosen. The resulting 45 models are visualised in Fig. 6. Hybrid gradient descent and least squares estimation learning was used for training. A comparison with ANN modelling similar to the approach described above by the same authors [40] showed that the prediction accuracy in terms of the standard deviation of the error was comparable. ANFIS required less time for training, however. For failure diagnosis, the prediction errors were averaged to daily values and compared with a probability limit of $0.01 \%$. An alarm was raised when at least three daily values violated the threshold within a week. Successful detection of a hydraulic oil leakage, gearbox oil temperature increases, converter fan malfunctions, an anemometer offset and a controller malfunction were demonstrated [51].

3.3.4 Other methodologies: Wang and Infield [52] proposed a non-parametric, non-linear state estimation technique (NSET) for NBM using SCADA data. This approach was based on an estimation of the target value by using a state memory matrix of inputs. The NSET algorithm uses a product of the memory matrix and a weighting vector to estimate each new operational state. The weighting vector was determined using a least squares approach for minimising the residuals of estimated and measured output utilising a Euclidean distance operator. The input variables considered for building the state memory matrix were chosen using physical understanding of the system and correlation analysis. A data selection algorithm was applied to reduce the number of states for each variable. Welchs's $t$-test, as a distance measure for samples with different variances, or a one-sided hypothesis test was used for anomaly detection.

In a case study, Wang and Infield investigated gearbox failures using 3 month of SCADA data from 10 turbines. Data from different turbines were used for training ( 7 turbines), validation (1 turbine) and testing data (2 turbines with failures). The target gearbox cooling oil temperature was modelled with the gearbox bearing temperature, the power output, the nacelle temperature and the oil temperature itself. Using this approach, alarms were reported almost a month before the final gearbox failures. A comparison with a four-input four-output ANN approach similar to $[23,24]$ demonstrated better performance for the NSET. Guo [53] 


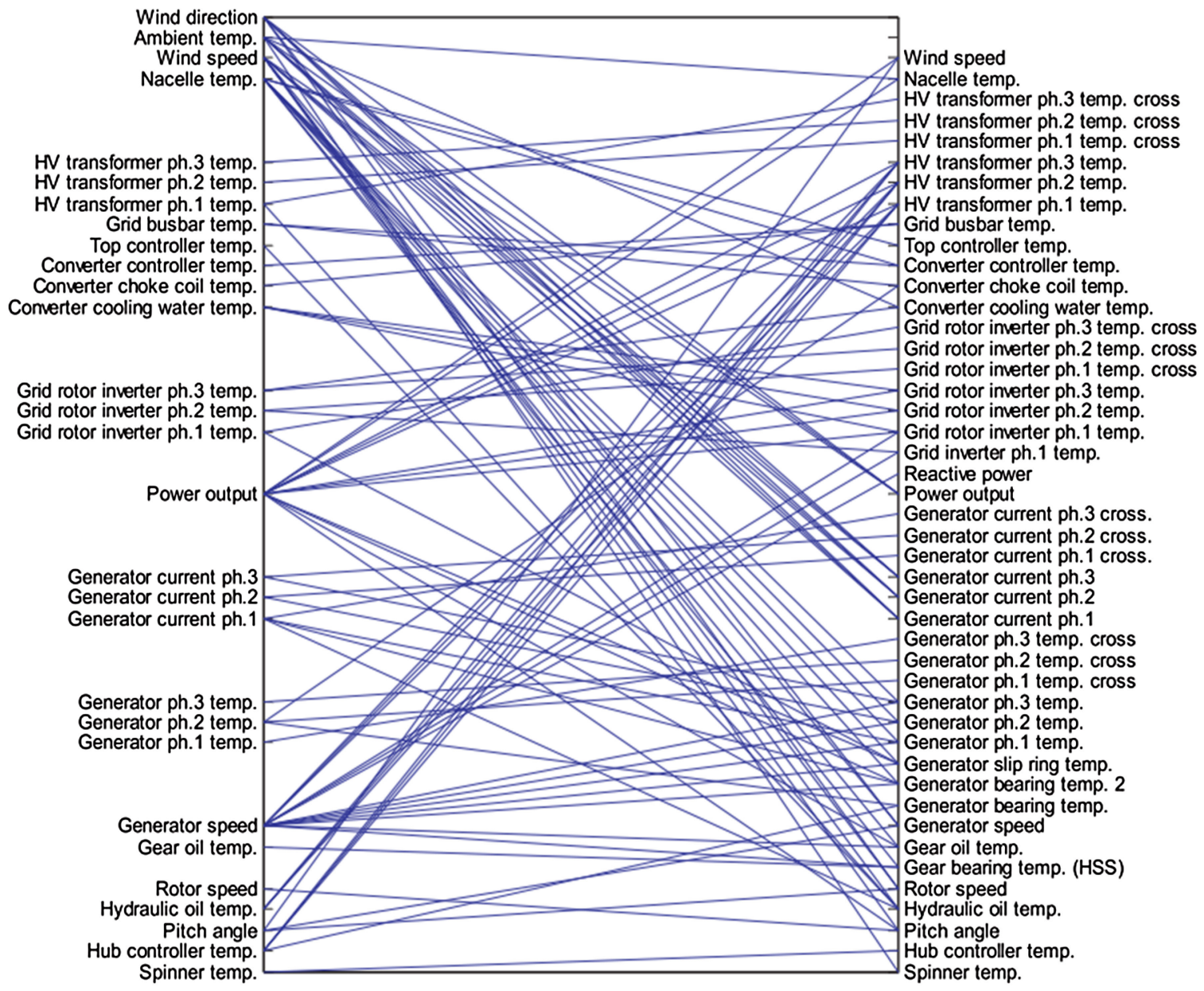

Fig. 6 Fuzzy modelling, input and outputs from [27]. Reprinted from [27], Copyright (2013) with permission from Elsevier

investigated NSET to model a generator bearing temperature, but did not actually apply the approach to failure detection.

Butler et al. [54] presented modelling based on sparse Bayesian learning of a configuration equivalent to ARX to predict the main bearing temperature. The model was defined as a weighted sum of radial basis functions. A threshold based on the residual distribution was used to detect fault conditions. The authors presented an estimation of remaining useful life with particle filtering (or sequential Monte Carlo) methods.

Cross and Ma [30] applied, as a third approach, a quasi-linear SDP model for NBM. The coefficients of determination were high for normal operations, i.e. 0.983 and 0.997 for the gearbox temperature and generator winding temperature, respectively. A three-dimensional surface built using the prediction model acted as an adaptive threshold for failure detection with fuzzy rules.

3.3.5 Discussion: Multiple studies have proven that NBM can be used to detect failures. Although the concept of evaluating a residual of measured minus modelled signal provides a failure indicator which is easy to interpret, the dependency on training data and manually set thresholds can result in undetected changes or frequent false alarms. The usage of a confidence factor based on training duration and accuracy as suggested in [28] might help to improve anomaly detection and assessment. Different NBM concepts as ARX and FSRC, different techniques based on linear models, ANN, ANFIS etc. and different anomaly detections as simple thresholds, Mahalanobis distance or health degree approaches have been tested, but sufficiently comprehensive comparisons are needed to evaluate which solution is best. Additionally, there is a need for a universal strategy to select inputs for NBM.

\subsection{Damage modelling}

The NBM approaches described above tend to be 'black-box' based with little or no insight into the physical processes which drive failure. Instead of comparing measured signals with empirical models of normal behaviour, interpreting measured signals using physical models can potentially better represent damage development and give more accurate results.

Gray and Watson [55] presented a physics of failure approach for damage calculation and failure probability estimation, i.e. developing a damage model based on a physical understanding of the particular failure mode of interest. For failure modes, which manifest themselves through accumulated damage, such as fatigue, the probability of an imminent breakdown can be estimated. The approach was applied in a field study using two years of SCADA data from a wind farm consisting of 160 fixed-speed $1 \mathrm{MW}$ turbines in order to study gearbox failures. Lundgren-Palmgren damage model for gearbox bearings was proposed and linear damage accumulation assumed. Constants were calibrated by comparison of the assumed design lifetime and the actual lifetime of the failed bearings. An assessment of the resulting damage in the full turbine distribution for the wind farm revealed that the failed turbines show higher damage values than $75 \%$ of the population, see Fig. 7. The widely distributed values showed that it would be difficult to accurately predict which turbines were about to fail, but nonetheless could be used to help prioritise maintenance actions within a large fleet of turbines. The approach was also applied to yaw failures for the same wind farm [26].

Breteler et al. [56] generated a general framework for a physics of failure approach as illustrated in Fig. 8. An additional load generator module was proposed to consider external factors. A gearbox failure in a helical gear due to bending fatigue of a gear tooth was investigated in a case study. Laser measurements of the misalignments were used to calculate loads using a finite element 


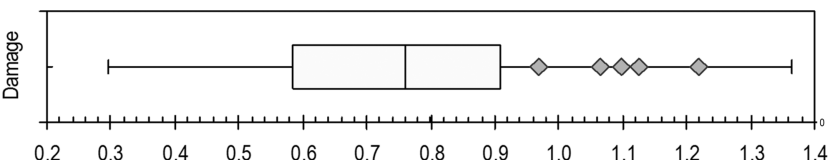

Fig. 7 Calculated bearing damage for 160 turbines from [55]. Box plot with extrema, quartiles and diamond symbols for failed turbines. Reprinted from [55], Copyright 2009 with permission of John Wiley and Sons, Ltd large differences not only between reference state and failure, but also between three different turbines.

Qiu et al. [57, 58] built a theoretical model for a turbine with gearbox and a DFIG based on thermodynamic principles and combined it with temperature trending approaches. Steady-state rotor aerodynamics was combined with simplified rigid drivetrain dynamics and an electromagnetic torque formula. In a case study of a 1.5 MW turbine, a gearbox gear teeth failure, a generator ventilation fault and generator winding unbalance were examined.

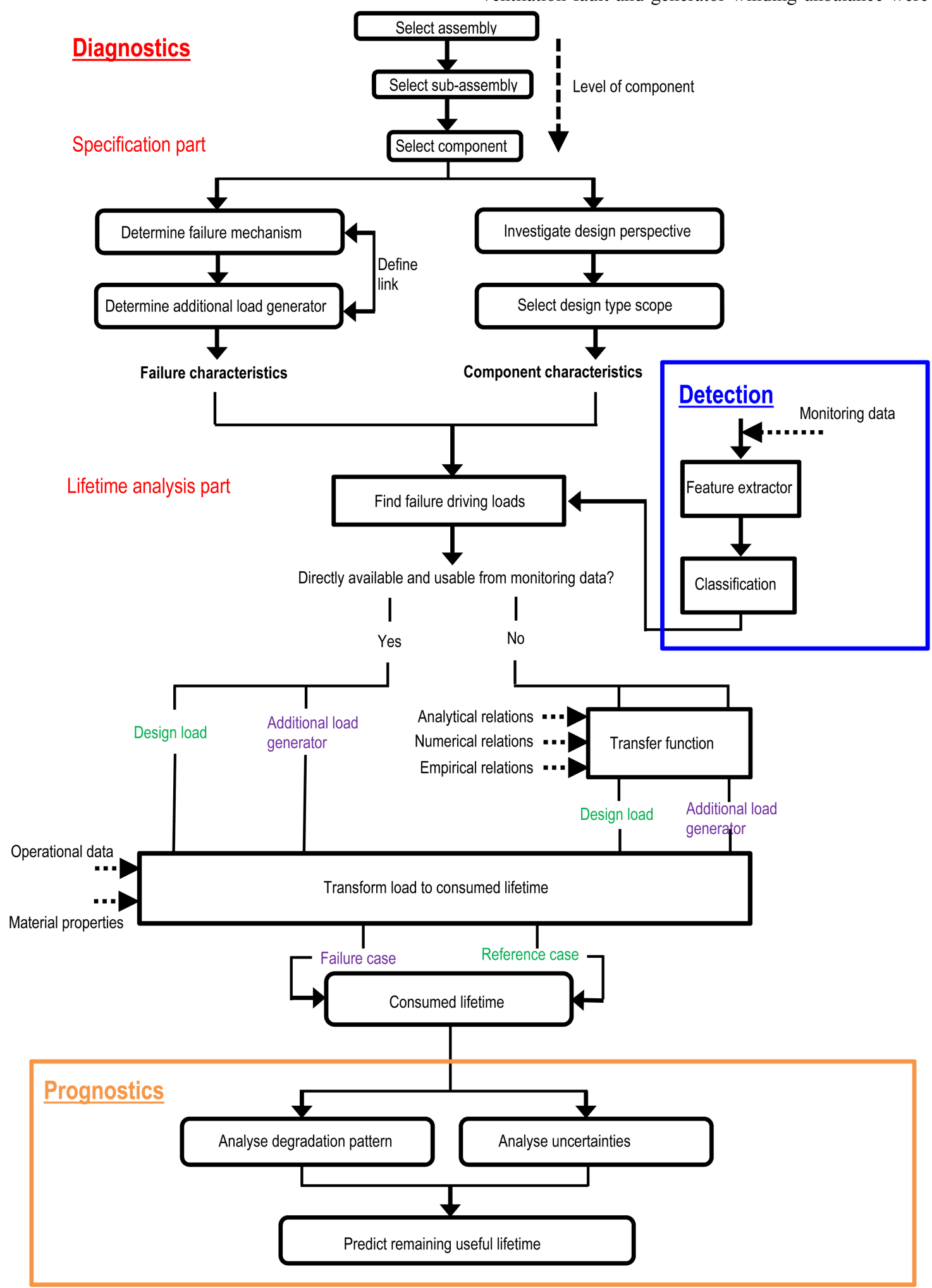

Fig. 8 Flowchart of Physics of Failure approach from [56]. Redrawn with permission of [56] Copyright 2015, MECAL IX

method calculation. Number of cycles and forces were calculated from averaged ten minute SCADA power output and generator speed measurements. The resulting remaining lifetime showed
SCADA data trends were used to validate the simulated degradation as shown in Fig. 9. Diagnostic rules were determined for the investigated faults based on the power transmission 


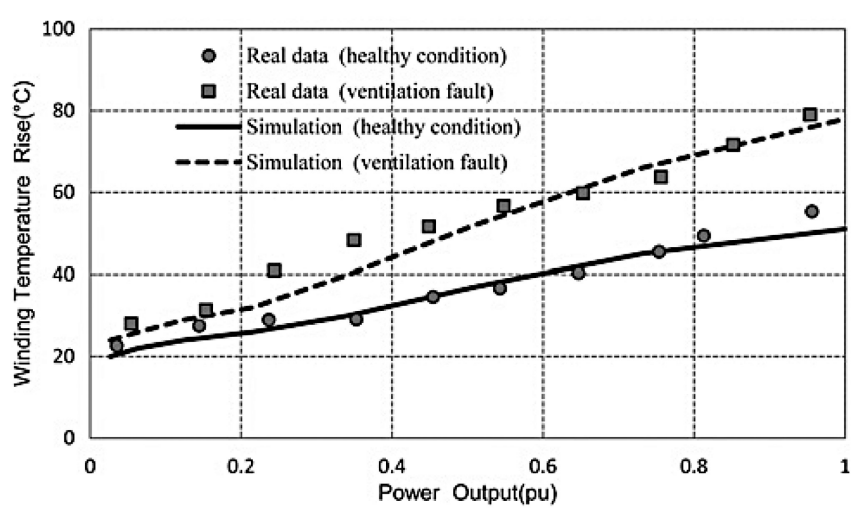

a

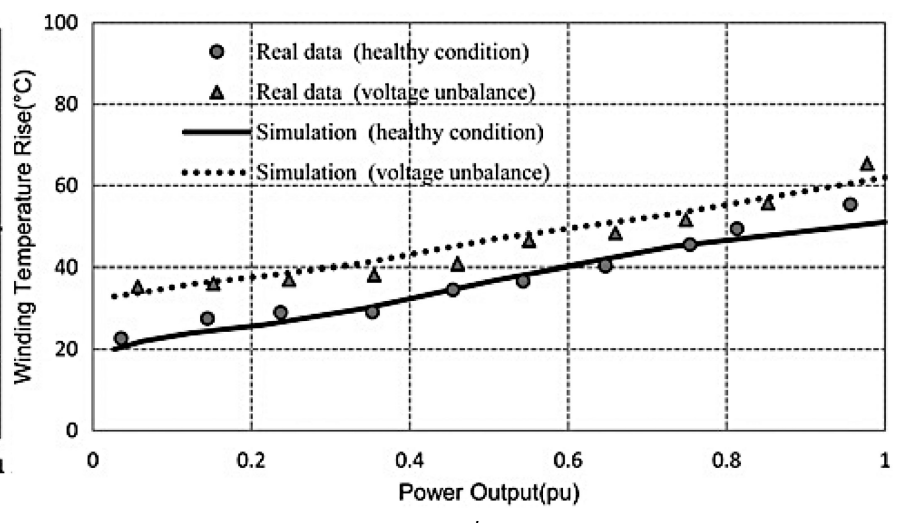

$b$

Fig. 9 DFIG degradation simulation in comparison with case study result from [58] Reprinted from [58], Copyright 2014, The IET (a) Ventilation fault, (b) Voltage unbalance

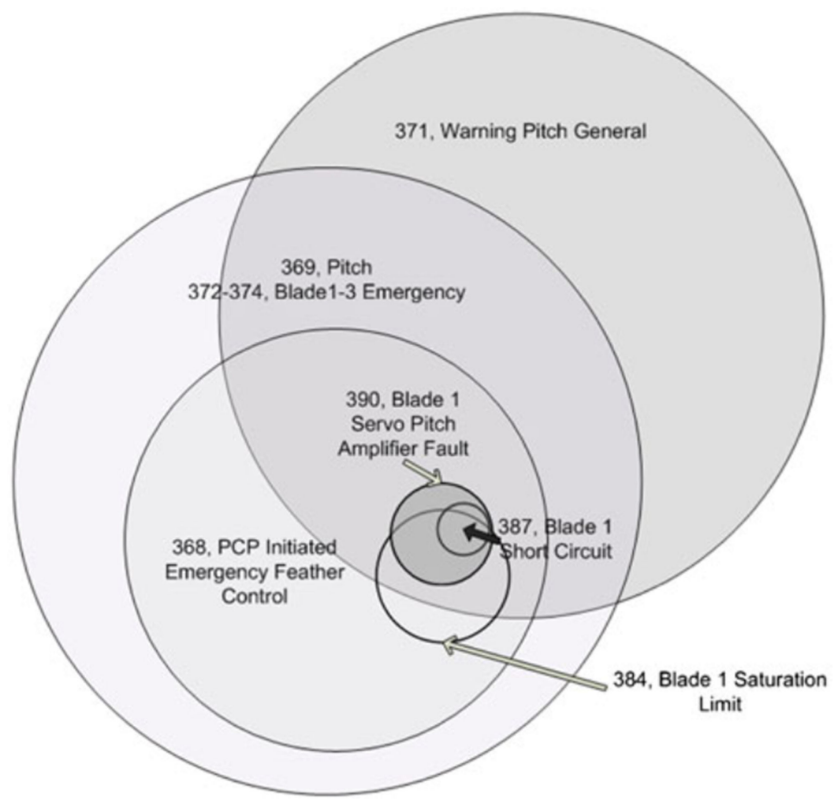

Fig. 10 Probability based Venn diagram analysis of pitch malfunction from [60]. The different circles represent alarms, intersections denote simultaneously occurring alarms. Here, the alarm 387 seems to be the origin of all other alarms. Reprinted from [60], Copyright (2011) with permission from John Wiley and Sons, Ltd

efficiency and generator winding or lubricant temperature gradients.

Borchersen and Kinnaert [59] developed a mathematical model for three generator coil temperatures. The model for the switching generator cooling and heating system was built without knowledge of the actual system. Parameters were found by applying an extended Kalman filter. The anomaly detection utilised residuals of model parameters for the different coils with a cumulative sum algorithm. In a case study with 3 years of SCADA data from 43 offshore turbines, 16 out of 18 cooling faults were successfully detected with only one false alarm.

Comparing measured signals with physical turbine or damage models has been successfully applied to fault detection, although challenges to get sufficient detection accuracy remain. Due to a lack of studies with sufficiently large numbers of failures, different failure modes or different turbines, the potential for using damage modelling in CM is not yet fully established.

\subsection{Assessment of alarms and expert systems}

Different systems have been proposed in order to better interpret outputs from SCADA control alarms or NBM results.

3.5.1 Status code processing: Qiu et al. [60] developed two approaches to reduce SCADA alarms based on up to two years of data from two different wind farms with more than 400 turbines in total and two different manufacturers. The different types of alarms were classified as general, system operation, environmental and communication/connection/software alarms. The average alarm rate was about $10-20$ per ten-minute interval, but high maximum rates of up to 1500 alarms per ten minutes occurred. Remotely resetting was possible for only about $24 \%$ of the alarms (considering only one turbine type). An alarm time-sequence analysis was used to identifying cases where one alarm triggered another. In a second approach, probabilities were analysed using Bayes' theorem and probabilistic patterns were compared using a Venn diagram. An example probability analysis is given in Fig. 10. Although the time-sequence analysis was found to be useful when few data were available, root causes were better identified with the probability based analysis.

Chen et al. [61] utilised a binary ANN to map from alarm pattern to faults. A hidden layer size of 50 neurons was found to be optimal in the prediction of a pitch fault. The training data included 221 alarm patterns of 31 SCADA alarms from one turbine with an electrical pitch system. Tests using alarms from four other turbines showed a detection accuracy of only $8-47 \%$. The training data dependency of this approach was highlighted and possible extrapolation errors discussed.

Chen et al. [62] continued the probabilistic approach [60] and proposed a Bayesian network to find root causes. Good reasoning capabilities were demonstrated with the same data. An example is given in Fig. 11.

Godwin and Matthews [22] post-processed SCADA status codes for the purpose of pitch fault detection. The expert system developed based on logical rules learned using a RIPPER algorithm was able to concentrate the amount of information.

Kusiak and $\mathrm{Li}$ [63] predicted status codes, their severity and specific code types (in this case, a malfunction of the diverter) by mapping codes to wind speed and power output. Training and testing data were taken from three months of SCADA data with five-minute resolution from four turbines. Neural network ensemble, standard classification, regression tree and boosting tree algorithm difference methods were found to extract the required information best. Faults were predicted 60 min ahead.

Chen et al. [64] utilised an a priori knowledge-based ANFIS to detect pitch faults. Based on six fault cases from two turbines, a knowledge base was built by finding relationships between rotor speed, blade angle, pitch motor torque and power output. This knowledge was included in the ANFIS structure to supplement modelling in cases of insufficient training data. Testing with maintenance records of 28 months from 26 turbines in a Spanish farm demonstrated the advantage of this approach compared with simple alarm counting. For a 21 days' prognostic horizon, the model detected $62.2 \%$ of the cases that required maintenance. Tests using data from a US wind farm with 160 fixed speed $1 \mathrm{MW}$ turbines resulted in less accurate fault prognosis, however [65]. Unclear maintenance reports, missing torque signals and curtailments due to low grid demands were seen as causes. 

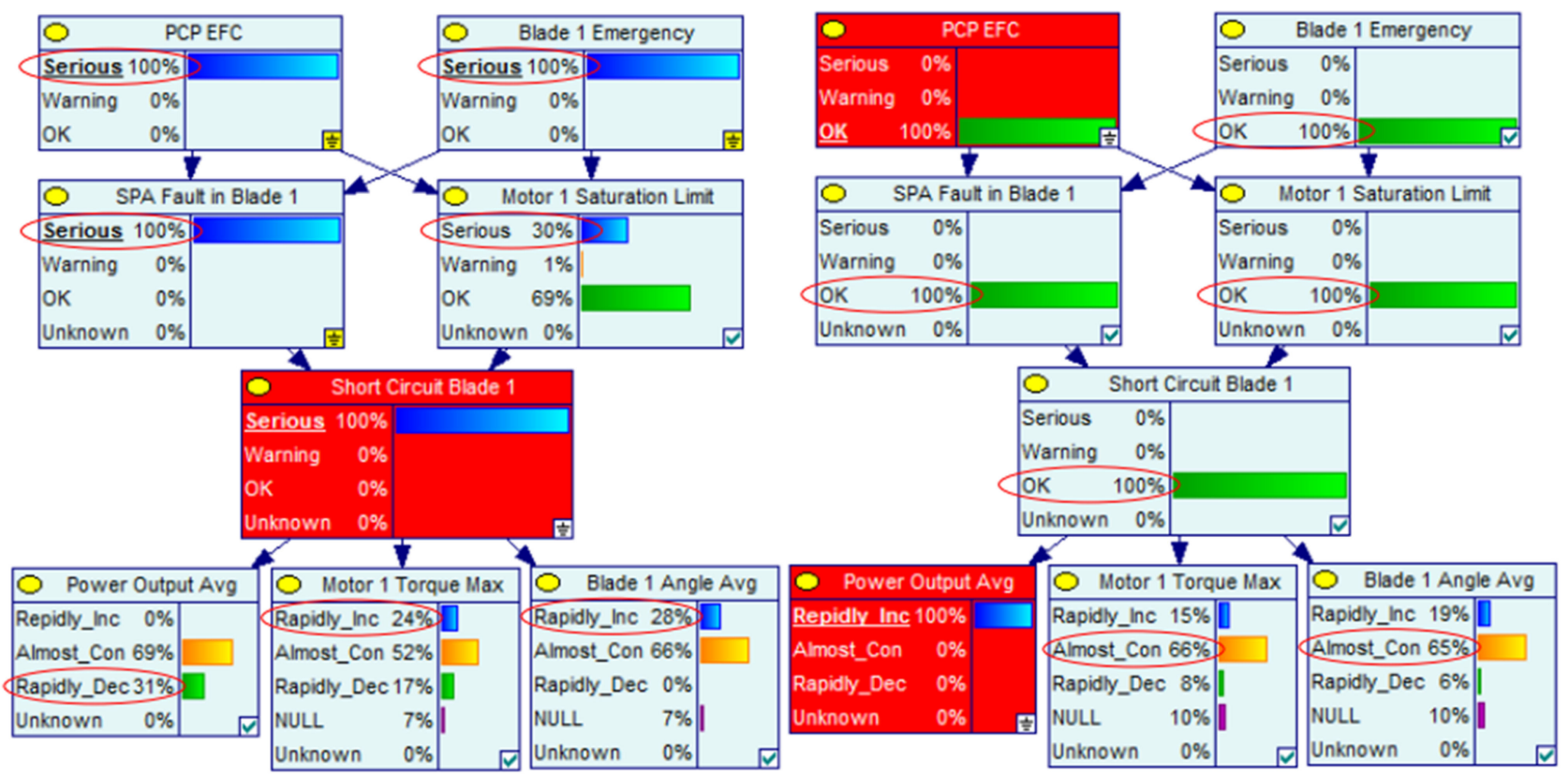

Fig. 11 Examples of Bayesian network reasoning from [62]. Reprinted with permission of [62]. Copyright 2012, Durham University (a) With pitch fault, (b) Without pitch fault

Turbine condition evolution during fan malfunction (WTG 14).

Co10-04-07
Component working as expected
$\begin{aligned} & \text { Converter choke coil temp. high } \\ & \text { Internal VCS fan not working/cooling } \\ & \text { insufficient }\end{aligned}$

Fig. 12 Example of fuzzy expert system output from [51] giving component status as green (ok), yellow (warning) and red (alarm) and possible root cause. Reprinted from [51], Copyright (2014) with permission from Elsevier

The evaluation of status codes for CM has been proven to be beneficial for better alarm assessment. However, the lack of any details concerning algorithms used in recent commercial products and the differences in status code generation of different software manufacturers hinders any clear assessment of the progress achieved in this field.

\subsubsection{Using expert systems to interpret alarms or modelling} results: Garcia et al. [23] applied an expert system to assess the output of their ANN modelling. Manually implemented fuzzy rules were used to diagnose causes of anomalies. The evolution of health was proposed to be used as a method for the prediction of remaining lifetime. Planning of maintenance as well as evaluation of its effectiveness and cost were also discussed. Failure history needed to be available for proper training of the system.

Cross and Ma [30] applied fuzzy inference to their temperature modelling. Trapezoidal and triangular membership functions based on fixed values for the residual size and duration were used to generate a three-stage status output.

Schlechtingen et al. [27] proposed an expert system to process their ANFIS modelling results. Prediction errors were passed to a fuzzy inference system only if three anomalies were detected by the daily probability threshold during one week. Triangular membership functions defined by occurrence probabilities and manual definitions in a master threshold table were used. Manually implemented fuzzy rules generated three stage condition statements as well as potential root causes, as shown in Fig. 12.

Li et al. [66] proposed a fuzzy assessment system, which was tested on a $850 \mathrm{~kW}$ variable speed turbine. A deterioration degree was defined using polynomial functions up to third order of the wind speed for setting normal limits of temperatures. Trapezoidal and triangular membership functions were used with weights for different temperatures to build a fuzzy synthetic assessment system with linguistic results from 'excellent' to 'danger'. A case study was presented including normal operation, a gearbox fault and a stop due to a high generator winding temperature.

Li et al. [46] and Sun et al. [29] used a similar framework of fuzzy synthetic evaluation to assess the results from several ANN models for different targets or based on different training data. Nine different faults were used for the allocation of the abnormal level indices to fuzzy memberships. The implementation of weights considered the share of each ANN model in the 'health degree' [46] and/or the prediction accuracy under normal conditions of the ANN models [29].

De Andrade Viera and Sanz-Bobi [67] proposed a risk indicator concept based on their ANN modelling [23]. Residuals of modelling were integrated over time, if the residual was outside a confidence band. Results of different ANN models were combined in a weighted sum based on quality of models. A cost-effective maintenance model was proposed adapted to the ongoing observed life with a variable threshold depending on a risk indicator growth rate.

Gray et al. [68] suggested abductive diagnosis to link SCADA errors or modelling results with expert knowledge. Assessed failure modes, their location, operational mode and resulting indicator changes were used to create a so-called Propositional Horn Clause Abduction Problem which is able to provide fault diagnoses using a computational process. 
The usage of expert systems clearly simplifies the interpretation of NBM results. Health degrees or risk indicators can play an important role in integrating SCADA CM approaches in maintenance strategies.

\subsection{Other applications}

Other applications of SCADA data beside classical CM include: power curve analyses, modelling and monitoring, e.g. with $\mathrm{k}$ nearest-neighbour [69], copula estimation [70], k-nearestneighbour, cluster centre fuzzy logic, ANN and ANFIS [71], ANN and Gaussian processes [72], linear and Weibull profiles definitions [73] or with stochastic methods [74]. Further references can be found in dedicated power curve modelling reviews, e.g. [75]. Spare part demand forecasting was investigated with a proportional hazards model utilising counts of temperature threshold violations from SCADA data [76]. More general load and structural health monitoring can also employ SCADA data as an additional source of information, e.g. [74, 77, 78]

\section{Discussion and conclusion}

Different approaches to utilise SCADA data for CM of WTs are reviewed in this paper grouped as (i) trending, (ii) clustering, (iii) NBM, (v) damage modelling and (vi) assessment of alarms and expert systems.

The simple trending of SCADA data has demonstrated good abilities to detect anomalies. Case specific configuration and interpretation seem to be required, however. Automated monitoring based on trending will most likely struggle to be accurate enough and avoid false alarms.

Clustering, as a more advanced technique of finding the differences between normal operation and anomaly, has the same disadvantage. Additionally, extensive historical failure data are required, if the methods are able to reliably diagnose failures. It is unlikely that the full range of fault stages will be available in any training data period in practice.

NBM has been the focus of recent research using SCADA data for $\mathrm{CM}$ due to the advantage of relatively easy anomaly detection using the residual of modelled minus measured variables after training under normal conditions. Models based on polynomial equations, ANN, ANFIS or NSET demonstrated good failure detection abilities. However, comprehensive comparisons of the techniques are lacking in order to be able to assess which technique is best. From the different studies, it is hard to assess whether a good accuracy and fault detection is based on a certain technique, on the NBM concept being ARX or FSRC, or even on further detailed settings. However, it is not satisfactorily shown that the (computational) effort of machine learning techniques like ANN, ANFIS or NSET is reasonable as only one case study compares linear modelling with ANN [40]. On the other hand, most publications criticising ANN training as too time-consuming do not consider the ongoing improvements in computational resources in common desktop computers. There is lack of published NBM performance metrics for different case studies in order to be able to properly evaluate required effort and performance in terms of normal behaviour prediction, true failure detections and false alarms for all of the techniques.

The damage modelling approaches show potential for $\mathrm{CM}$ of WTs focussing on physical causes of failures. However, the development of reliable and accurate damage models for all failure modes of a WT will be a very difficult task. As only a few studies have been published in this area, the feasibility of using such models for online monitoring of different turbines, possibly from different manufacturers and in different locations, cannot be assessed yet.

Status code processing with probabilistic approaches or physical rules shows promise to condense a large number of alarms into helpful information. However, the studies reviewed do not discuss recent industrial developments, which might have already solved problems discussed. Expert systems with fuzzy inference can be used to automate interpretation of modelling results and deliver easy to understand outputs. Complete asset monitoring and maintenance planning will require assessment of monitoring alarms and decision making as supported by such systems.

This review focuses on techniques which have been already applied to real SCADA data. Fig. 13 gives a summary of the reviewed SCADA CM approaches with respect to WT type described by rated power, the amount of data expressed in WT years, the number of investigated failures or anomalies and the subassembly or part of interest. It can be seen, that nearly all research has been based on relatively old WT technology with WTs in the range 1-2 MW. The majority of the case studies reviewed based their results on a relatively small amount of data, with less than $30 \mathrm{WT}$ years of SCADA data. Only four case studies were based on more than 10 failures. Most of the approaches focused on detecting failures in gearboxes or bearings.

Based on the presented review of recent $\mathrm{CM}$ approaches with SCADA data, future research should initially address the following:

- comparing the prediction accuracy of different approaches as many publications have claimed to have the best solution for SCADA CM, but do not comprehensively compare them with other techniques;

- validating approaches on modern multi-MW WTs, because all studies up to date have used relatively old turbines;

- testing approaches using data from a range of different wind farms and turbine types as most studies have only considered one farm or one WT manufacturer.

For future studies, emphasis should be put on providing sufficient metrics, true and false failure detection rates, advance detection times and computational effort to allow better comparison between SCADA analysis techniques. In terms of data-driven training, the demonstration of a few successful failure detections alone is not sufficient as the practical use is determined by the reliability of the approach, i.e. in particular the detection rate and false alarms for new data.

Further potential is seen in future research concerning:

i. NBM:

- comparing ARX and FSRC concepts independent of modelling technique

- finding sufficient training length and universal input selection algorithm

- validating ANN training and updating algorithm [48] on bigger scale and for other techniques

- evaluating NSET with more data

- testing of linear, ANN or NSET modelling for multiple targets beside temperatures as done with ANFIS [27]

- comparing different anomaly detection techniques such as using a Mahalanobis distance [47], a health degree based on probability $[29,46]$, multiple alarms over a given period [27], etc., independent of modelling technique

- investigating 'black-box' information from models: do the model parameters provide helpful information?

ii. Damage modelling:

- testing and validating damage models with different turbines

- investigating possible merging of Physics of Failure models with 'black box' NBM

- developing new damage models for turbine components not yet studied

- using high resolution SCADA data for damage modelling to provide higher damage accumulation accuracy

iii. Assessment of alarms and status codes:

- applying status code processing approaches subassemblies besides the pitch system

- investigating current state-of-the art in industrial SCADA processing systems. 


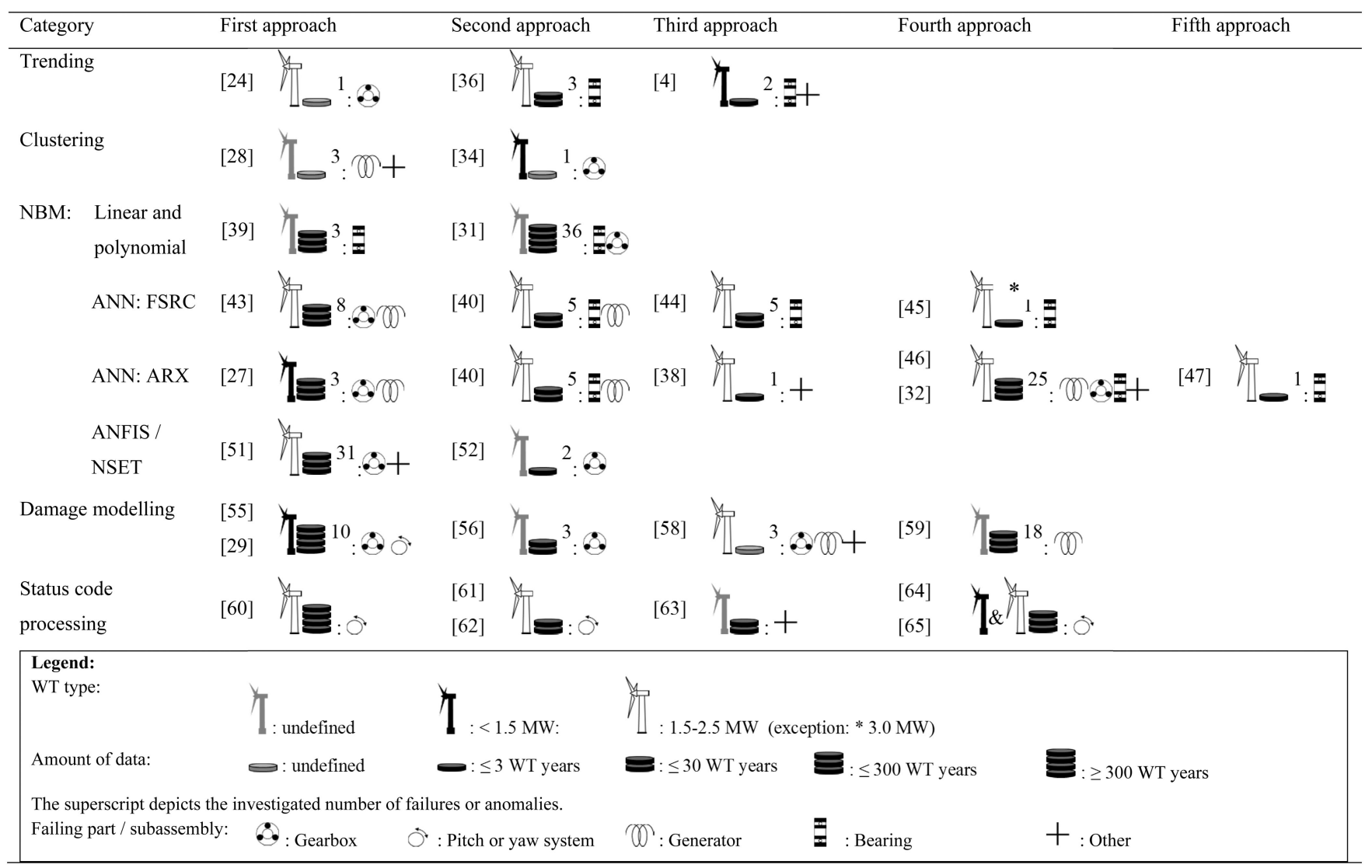

Fig. 13 Summary of different SCADA CM approaches and WT type investigated, data used, number of anomalies and subassembly of interest. Only approaches in the focus of a paper and with at least one investigated failure from real data are listed

\section{Acknowledgments}

This project has received funding from the European Union's Horizon 2020 research and innovation programme under the Marie Sklodowska-Curie grant agreement No 642108 (project AWESOME).

\section{References}

[1] Global Wind Energy Council: 'Global Wind Statistics 2015'. Available at http://www.gwec.net/wp-content/uploads/vip/GWEC-

PRstats-2015_LR_corrected.pdf, accessed 29 March 2016

[2] Tavner, P.: 'Offshore wind turbines: reliability, availability and maintenance' (The Institution of Engineering and Technology, London, 2012)

[3] Milborrow, D.: 'The tide turns on offshore maintenance costs'. Available at http://www.windpoweroffshore.com/article/1314299/tide-turns-offshoremaintenance-costs, accessed 29 March 2016

[4] Yang, W., Court, R., Jiang, J.: 'Wind turbine condition monitoring by the approach of SCADA data analysis', Renew. Energy, 2013, 53, (5), pp. 365376

[5] Yang, W., Tavner, P.J., Crabtree, C.J., et al.: 'Wind turbine condition monitoring: technical and commercial challenges', Wind Energy, 2014, 17, (5), pp. 673-693

[6] Hameed, Z., Hong, Y.S., Cho, Y.M., et al.: 'Condition monitoring and fault detection of wind turbines and related algorithms: A review', Renew. Sustain. Energy Rev., 2009, 13, (1), pp. 1-39

[7] García Márquez, F.P., Tobias, A.M., Pinar Pérez, J.M., et al.: 'Condition monitoring of wind turbines: Techniques and methods', Renew. Energy, 2012, 46, pp. $169-178$

[8] Purarjomandlangrudi, A., Nourbakhsh, G., Esmalifalak, M., et al.: 'Fault detection in wind turbine: a systematic literature review', Wind Eng., 2013, 37, (5), pp. 535-548

[9] Tchakoua, P., Wamkeue, R., Ouhrouche, M., et al.: 'Wind turbine condition monitoring: state-of-the-art review, new trends, and future challenges', Energies, 2014, 7, (4), pp. 2595-2630

[10] Qiao, W., Lu, D.: 'A survey on wind turbine condition monitoring and fault diagnosis - part i: components and subsystems', IEEE Trans. Ind. Electron., 2015, 62, (10), pp. 6536-6545

[11] Qiao, W., Lu, D.: 'A survey on wind turbine condition monitoring and fault diagnosis - part ii: signals and signal processing methods', IEEE Trans. Ind. Electron., 2015, 62, (10), pp. 6546-6557

[12] Hahn, B., Durstewitz, M., Rohrig, K.: 'Reliability of wind turbines experience of 15 years with 1500 WTs', in 'Wind energy' (Springer, 2007),
[13] Ribrant, J., Bertling, L.M.: 'Survey of failures in wind power systems with focus on Swedish wind power plants during 1997-2005', IEEE Trans. Energy Convers., 2007, 22, (1), pp. 167-173

[14] Tavner, P.J., Xiang, J., Spinato, F.: 'Reliability analysis for wind turbines', Wind Energy, 2007, 10, (1), pp. 1-18

[15] Spinato, F., Tavner, P.J., van Bussel, G.J.W., et al.: 'Reliability of wind turbine subassemblies', IET Renew. Power Gener., 2009, 3, (4), pp. 1-15

[16] Pinar Pérez, J.M., García Márquez, F.P., Tobias, A., et al.: 'Wind turbine reliability analysis', Renew. Sustain. Energy Rev., 2013, 23, pp. 463-472

[17] Feng, Y., Tavner, P.J., Long, H.: 'Early experiences with UK round 1 offshore wind farms', Proc. Inst. Civ. Eng. - Energy, 2010, 163, (4), pp. 167-181

[18] Wilkinson, M., Harman, K.: 'Measuring wind turbine reliability, results of the reliawind project'. EWEA Annual Conf. 2011, 2011

[19] Sheng, S.: 'Report on wind turbine subsystem reliability - a survey of various databases' (National Renew. Energy Lab, 2013)

[20] Carroll, J., McDonald, A., McMillan, D.: 'Reliability comparison of wind turbines with DFIG and PMG drive trains', IEEE Trans. Energy Convers. 2015, 30, (2), pp. 663-670

[21] Carroll, J., McDonald, A., McMillan, D.: 'Failure rate, repair time and unscheduled O\&M cost analysis of offshore wind turbines', Wind Energy, 2015, 17, (6), pp. 1107-1119

[22] Godwin, J.L., Matthews, P.: 'Classification and detection of wind turbine pitch faults through SCADA data analysis', Int. J. Progn. Heal. Manag., 2013, 4, pp. 1-11

[23] Garcia, M.C., Sanz-Bobi, M.A., del Pico, J.: 'SIMAP: intelligent system for predictive maintenance application to the health condition monitoring of a windturbine gearbox', Comput. Ind., 2006, 57, (6), pp. 552-568

[24] Zaher, A., McArthur, S.D. J., Infield, D.G., et al: 'Online wind turbine fault detection through automated SCADA data analysis', Wind Energy, 2009, 12, (6), pp. 574-593

[25] Catmull, S.: 'Self-organising map based condition monitoring of wind turbines'. EWEA Annual Conf. 2011, 2011

[26] Watson, S.J., Kennedy, I., Gray, C.S.: 'The use of physics of failure modelling in wind turbine condition monitoring'. EWEA Annual Conf. 2011, 2011, pp. 309-312

[27] Schlechtingen, M., Santos, I.F., Achiche, S.: 'Wind turbine condition monitoring based on SCADA data using normal behavior models. Part 1: system description', Appl. Soft Comput., 2013, 13, (1), pp. 259-270

[28] Wilkinson, M., Harman, K., van Delft, T., et al.: 'Comparison of methods for wind turbine condition monitoring with SCADA data', IET Renew. Power Gener., 2014, 8, (4), pp. 390-397

[29] Sun, P., Li, J., Wang, C. et al: 'A generalized model for wind turbine anomaly identification based on SCADA data', Appl. Energy, 2016, 168, pp. 550-567

[30] Cross, P., Ma, X.: 'Model-based and fuzzy logic approaches to condition monitoring of operational wind turbines', Int. J. Autom. Comput., 2015, 12, (1), pp. 25-34 
[31] Feng, Y., Qiu, Y., Crabtree, C.J., et al.: 'Monitoring wind turbine gearboxes', Wind Energy, 2013, 16, (5), pp. 728-740

[32] Crabtree, C.J., Zappalá, D., Tavner, P.J.: 'Survey of commercially available condition monitoring systems for wind turbines' (Durham University School of Engineering and Computing Sciences and the SUPERGEN Wind Energy Technologies Consortium, 2014)

[33] Wiggelinkhuizen, E., Verbruggen, T., Braam, H., et al.: 'Assessment of condition monitoring techniques for offshore wind farms', J. Sol. Energy Eng., 2008, 130, (3), pp. 031004-1-031004-9

[34] Kim, K., Parthasarathy, G., Uluyol, O., et al.: 'Use of SCADA data for failure detection in wind turbines'. ASME 5th Int. Conf. Energy Sustain., 2011, pp. 2071-2079

[35] Feng, Y., Qiu, Y., Crabtree, C., et al.: 'Use of SCADA and CMS signals for failure detection and diagnosis of a wind turbine gearbox'. EWEA Annual Conf. 2011, 2011

[36] Astolfi, D., Castellani, F., Terzi, L.: 'Fault prevention and diagnosis through scada temperature data analysis of an onshore wind farm', Diagnostyka, 2014, 15, (2), pp. 71-78

[37] Kusiak, A., Zhang, Z.: 'Analysis of wind turbine vibrations based on SCADA data', J. Sol. Energy Eng., 2010, 132, (3), pp. 031008-1-031008-12

[38] Zhang, Z., Kusiak, A.: 'Monitoring wind turbine vibration based on SCADA data', J. Sol. Energy Eng., 2012, 134, (2), pp. 021004-1-021004-12

[39] Garlick, W.G., Dixon, R., Watson, S.J.: 'A model-based approach to wind turbine condition monitoring using SCADA data'. 20th Int. Conf. System Engineering, 2009

[40] Schlechtingen, M., Santos, I.F.: 'Comparative analysis of neural network and regression based condition monitoring approaches for wind turbine fault detection', Mech. Syst. Signal Processing, 2010, 25, pp. 1849-1875

[41] Du, H.: 'Data mining techniques and applications: an introduction' (Cengage Learning EMEA, 2010)

[42] Brandão, R.F.M., Carvalho, J.A.B., Barbosa, F.P.M.: 'Neural networks for condition monitoring of wind turbines'. Int. Symp. Modern Electric Power System Wroclaw, Poland, 2010

[43] Brandão, R.F.M., Carvalho, J.A.B.: 'Intelligent system for fault detection in wind turbines gearbox'. PowerTech Eindhoven 2015, 2015

[44] Kusiak, A., Verma, A.: 'Analyzing bearing faults in wind turbines: a datamining approach', Renew. Energy, 2012, 48, pp. 110-116

[45] Zhang, Z.-Y., Wang, K.-S.: 'Wind turbine fault detection based on SCADA data analysis using ANN', Adv. Manuf., 2014, 2, (1), pp. 70-78

[46] Li, J., Lei, X., Li, H., et al.: 'Normal behavior models for the condition assessment of wind turbine generator systems', Electr. Power Compon. Syst., 2014, 42, (11), pp. 1201-1212

[47] Bangalore, P., Tjernberg, L.B.: 'An artificial neural network approach for early fault detection of gearbox bearings', IEEE Trans. Smart Grid, 2015, 6, (2), pp. 980-987

[48] Bangalore, P., Tjernberg, L.B.: 'An approach for self evolving neural network based algorithm for fault prognosis in wind turbine'. 2013 IEEE Grenoble Conf., 2013

[49] Bangalore, P., Tjernberg, L.B.: 'Self evolving neural network based algorithm for fault prognosis in wind turbines: A case study'. 2014 Int. Conf. Probabilistic Methods Application to Power Syst. (PMAPS), 2014

[50] Jang, J.-S.R., Sun, C.-T., Mizutani, E.: 'Neuro-fuzzy and soft computing: a computational approach to learning and machine intelligence' (Prentice Hall, 1997)

[51] Schlechtingen, M., Santos, I.F.: 'Wind turbine condition monitoring based on SCADA data using normal behavior models. Part 2: Application examples', Appl. Soft Comput., 2014, 14, (1), pp. 447-460

[52] Wang, Y., Infield, D.: 'Supervisory control and data acquisition data-based non-linear state estimation technique for wind turbine gearbox condition monitoring', IET Renew. Power Gener, 2012, 7, (4), pp. 350-358

[53] Guo, P.: 'Wind turbine generator bearing condition monitoring with NEST method'. Proc. 2012 24th Chinese Control Decision Conf. CCDC 2012, 2012, pp. 235-239

[54] Butler, S., O'Connor, F., Farren, D., et al.: 'A feasibility study into prognostics for the main bearing of a wind turbine'. Proc. IEEE Int. Conf. Control Application, 2012, pp. 1092-1097

[55] Gray, C.S., Watson, S.J.: 'Physics of Failure approach to wind turbine condition based maintenance', Wind Energy, 2010, 13, (5), pp. 395-405

[56] Breteler, D., Kaidis, C., Loendersloot, R.: 'Physics based methodology for wind turbine failure detection, diagnostics \& prognostics'. EWEA 2015 Annual Event, 2015

[57] Qiu, Y., Zhang, W., Cao, M., et al.: 'An electro-thermal analysis of a variablespeed doubly-fed induction generator in a wind turbine', Energies, 2015, 8, (5), pp. 3386-3402

[58] Qiu, Y., Feng, Y., Sun, J., et al.: 'Applying thermophysics for wind turbine drivetrain fault diagnosis using SCADA data'. IET Renew. Power Gener., 2016, 10, (5), pp. 1-8

[59] Borchersen, A.B., Kinnaert, M.: 'Model-based fault detection for generator cooling system in wind turbines using SCADA data', Wind Energy, 2016, 19, (4), pp. 593-606

[60] Qiu, Y., Feng, Y., Tavner, P., et al.: 'Wind turbine SCADA alarm analysis for improving reliability', Wind Energy, 2012, 15, (8), pp. 951-966

[61] Chen, B., Qiu, Y.N., Feng, Y., et al.: 'Wind turbine SCADA alarm pattern recognition'. IET Conf. Renewable Power Generation (RPG 2011), 2011, pp. 363-368

[62] Chen, B., Tavner, P., Feng, Y., et al.: 'Bayesian network for wind turbine fault diagnosis'. EWEA 2012 Copenhagen, 2012

[63] Kusiak, A., Li, W.: 'The prediction and diagnosis of wind turbine faults', Renew. Energy, 2011, 36, (1), pp. 16-23

[64] Chen, B., Matthews, P.C., Tavner, P.J.: 'Wind turbine pitch faults prognosis using a-priori knowledge-based ANFIS', Expert Syst. Appl., 2013, 40, (17), pp. $6863-6876$
[65] Chen, B., Matthews, P.C., Tavner, P.J.: 'Automated on-line fault prognosis for wind turbine pitch systems using supervisory control and data acquisition', IET Renew. Power Gener., 2015, 9, (5), pp. 503-513

[66] Li, H., Hu, Y.G., Yang, C., et al.: 'An improved fuzzy synthetic condition assessment of a wind turbine generator system', Int. J. Electr. Power Energy Syst., 2013, 45, (1), pp. 468-476

[67] De Andrade Vieira, R.J., Sanz-Bobi, M.A.: 'Failure risk indicators for a maintenance model based on observable life of industrial components with an application to wind turbines', IEEE Trans. Reliab., 2013, 62, (3), pp. 569-582

[68] Gray, C.S., Koitz, R., Psutka, S., et al.: 'An abductive diagnosis and modeling concept for wind power plants', IFAC-PapersOnLine, 2015, 48, (21), pp. 404-409

[69] Kusiak, A., Zheng, H., Song, Z.: 'Models for monitoring wind farm power', Renew. Energy, 2009, 34, (3), pp. 583-590

[70] Gill, S., Stephen, B., Galloway, S.: 'Wind turbine condition assessment through power curve copula modeling', IEEE Trans. Sustain. Energy, 2012, 3 (1), pp. 94-101

[71] Schlechtingen, M., Santos, I.F., Achiche, S.: 'Using data-mining approaches for wind turbine power curve monitoring: A comparative study', IEEE Trans. Sustain. Energy, 2013, 4, (3), pp. 671-679

[72] Papatheou, E., Dervilis, N., Maguire, A.E., et al.: 'Wind turbine structural health monitoring: a short investigation based on SCADA data'. EWSHM 7th European Workshop Structural Health Monitoring, 2014

[73] Long, H., Wang, L., Zhang, Z., et al.: 'Data-driven wind turbine power generation performance monitoring', IEEE Trans. Ind. Electron., 2015, 62 (10), pp. 6627-6635

[74] Wächter, M., Lind, P.G., Hernandez, I.H., et al.: 'Efficient load and power monitoring by stochastic methods'. EWEA 2015 Annual Event, 2015

[75] Lydia, M., Kumar, S.S., Selvakumar, A.I., et al.: 'A comprehensive review on wind turbine power curve modeling techniques', Renew. Sustain. Energy Rev. 2014, 30, pp. 452-460

[76] Tracht, K., Goch, G., Schuh, P., et al.: 'Failure probability prediction based on condition monitoring data of wind energy systems for spare parts supply', CIRP Ann. - Manuf. Technol., 2013, 62, (1), pp. 127-130

[77] Obdam, T.S., Rademakers, L.W.M.M., Braam, H.: 'Flight leader concept for wind farm load counting: offshore evaluation', Wind Eng., 2010, 34, (1), pp. $109-122$

[78] Smolka, U., Cheng, P.W.: 'On the design of measurement campaigns for fatigue life monitoring of offshore wind turbines'. Twenty-third Int. Offshore Polar Engineering Conf., 2013, vol. 9, pp. 408-413 